\title{
Striatal dopamine release stimulated by amphetamine or potassium: influence of ovarian hormones and the light-dark cycle
}

\author{
JILL B. BECKER, MARY E. BEER and TERRY E. ROBINSON \\ Psychology Department and Neuroscience Laboratory Building, The University of Michigan, Ann Arbor, MI 48109 (U.S.A.)
}

(Accepted May 22nd, 1984)

Key words: dopamine - amphetamine - estrogen — progesterone — circadian rhythms - dopamine release - striatum

\begin{abstract}
The release of endogenous dopamine (DA) from rat striatal tissue was studied in an in vitro superfusion system following hormonal manipulations in vivo. Progesterone treatment in estrogen-primed ovariectomized female rats potentiated DA release stimulated either by amphetamine or potassium $\left(\mathrm{K}^{+}\right)$. In addition, the amount of striatal DA released in response to $\mathrm{K}^{+}$-stimulation was influenced by the light-dark cycle. We conclude that striatal DA release is modulated by ovarian hormones, and suggest that ovarian hormone modulation of presynaptic striatal DA activity may contribute to well-known estrous cycle dependent variations in some non-reproductive behaviors.
\end{abstract}

Endogenous ovarian steroid hormones may influence the functional activity of mesostriatal dopamine (DA) neurons by modulating presynaptic DA activity ${ }^{1,4}$. For example, in the female rat, treatment with a synthetic estrogen-progesterone combination increases DA synthesis and turnover ${ }^{1}$. In addition, the amphetamine (AMPH)-stimulated release of endogenous DA from striatal tissue in vitro varies with the estrous cycle, and is attenuated by ovariectomy $(\mathrm{OVX})^{4}$. Progesterone treatment in estrogen-primed OVX rats reinstates normal levels of AMPH-stimulated striatal DA release ${ }^{4}$. However, it is not known whether this effect of ovarian hormones is specific to AMPH-stimulated DA release. To understand how ovarian hormones influence striatal DA release, it is important to determine if they also modulate the release of DA stimulated by other mechanisms. In the experiment reported here we compared the influence of progesterone treatment in estrogen-primed OVX rats on AMPH-stimulated non-vesicular DA release ${ }^{15}$ with the exocytotic DA release induced by depolarization with high extracellular concentrations of potassium $\left(\mathrm{K}^{+}\right)$. In preliminary studies, we noted that the light-dark cycle had an influence on DA release. Therefore, the effects of ovarian hormones on striatal DA release were studied under 2 different lighting conditions.

Adult female Holtzman rats (Madison, WI) were individually housed on a $14 \mathrm{~h}-10 \mathrm{~h}$, light-dark cycle in 1 of 2 colony rooms: (1) normal light-dark cycle, lights on at $06.00 \mathrm{~h}$; (2) reversed light-dark cycle, lights off $08.30 \mathrm{~h}$. Two weeks after OVX the animals received either 3 daily injections (s.c.) of peanut oil $(0.1 \mathrm{ml})$ or $5.0 \mu \mathrm{g}$ estradiol benzoate $(\mathrm{EB})$ in peanut oil. On the 4th day they received an injection of either oil or $1.2 \mathrm{mg}$ of progesterone $(\mathrm{P})$ in oil between 06.00 and $09.00 \mathrm{~h}$, and were then decapitated $4 \mathrm{~h}$ later. Therefore, half of the animals were killed when lights were on in the colony room (OVX[oil]: light, $\mathrm{n}=6$; and $\mathrm{OVX}[\mathrm{EB}+\mathrm{P}]$ :light, $\mathrm{n}=5)$ and half when the lights were off (OVX[oil]:dark, $n=5$; and OVX $[E B+P]:$ dark, $n=5$ ).

Following decapitation, striatal tissue was rapidly removed from the brain, chopped into $1 \mathrm{~mm}^{3}$ pieces and placed in a superfusion chamber that was positioned in a constant temperature bath $\left(37^{\circ} \mathrm{C}\right)$. A modified Krebs-Ringer phosphate medium ( $\mathrm{pH} \mathrm{7.4)}$ flowed through the chamber at a rate of $100 \mu \mathrm{l} / \mathrm{min}$. After a 75-min stabilization period, samples of the effluent were collected over 5 -min intervals. These ef-

Correspondence: J. B. Becker, Neuroscience Laboratory Building, 1103 E. Huron, Ann Arbor, MI 48104, U.S.A. 
fluent samples were assayed for DA concentrations by high performance liquid chromatography with electrochemical detection. (For a detailed description of techniques see ref. 7). Normal medium was infused for the first $5 \mathrm{~min}$ (interval 1). At the beginning of interval 2, medium containing $10 \mu \mathrm{M} \mathrm{D}$-amphetamine sulfate (AMPH) was infused for $2.5 \mathrm{~min}$. followed by normal medium through interval 6 . At the beginning of the 7th interval, medium containing $60 \mathrm{mM} \mathrm{K}^{+}\left(\mathrm{Na}^{+}\right.$in the medium was reduced $)$was infused for $2.5 \mathrm{~min}$, followed by normal medium through interval 9. These doses and infusion times were based on extensive dose-response studies con-

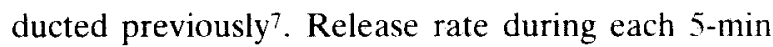
interval was expressed as $\mathrm{pg} \mathrm{DA} / \mathrm{mg}$ tissue/min. The data were analyzed by 2 separate three-way analyses of variance, the 3 factors being: (1) hormone treatment (oil vs EB $+\mathrm{P}$ ); (2) light cycle (light vs dark); and (3) time (intervals $1-5$ were analyzed to evaluate the effect of AMPH on DA release, and intervals 6-9 were analyzed to evaluate the effects of $K^{+}$stimulation).

There were no differences between the 4 groups in the basal rate (interval 1) of endogenous DA efflux (OVX[oil]:light $12.8 \pm 2.3, \mathrm{pg} / \mathrm{mg} / \mathrm{min} \pm$ S.E.M.; OVX[EB+P]:light 13.5 \pm 3.3; OVX[oil]:dark 10.1 \pm 1.6; OVX $[\mathrm{EB}+\mathrm{P}]$ :dark $10.4 \pm 2.3 ; F(3,17)=$ 0.56). As expected, $10 \mu \mathrm{M}$ AMPH infusion stimulated the release of DA in all groups $(F(3,51)=45.3$, $P<0.001$; Fig. 1). However, animals pretreated with estrogen plus progesterone released significantly more DA in response to AMPH stimulation than did oil-treated controls (hormone treatment $\times$ time interaction, $F(4,68)=3.22, P=0.017$; see Fig. 1). Although this effect of hormone treatment was independent of the light cycle (hormone treatment $\times$ light cycle $\times$ time interaction, $F(4,68)=0.68)$, there was a non-significant trend for AMPH-stimulated DA release to be higher in animals killed in the light than in those killed in the dark $(F(4,68)=2.03, P=$ 0.098).

Depolarization of striatal tissue with $\mathrm{K}^{+}$also stimulated the release of DA in all groups $(F(3,51)=$ 45.3, $P<0.001$; Fig. 1). However, $\mathrm{K}^{+}$-stimulated DA release was influenced by both hormone treatment and the light-dark cycle. Animals pretreated with estrogen plus progesterone released significantly more DA in response to $\mathrm{K}^{+}$-induced depolariza-

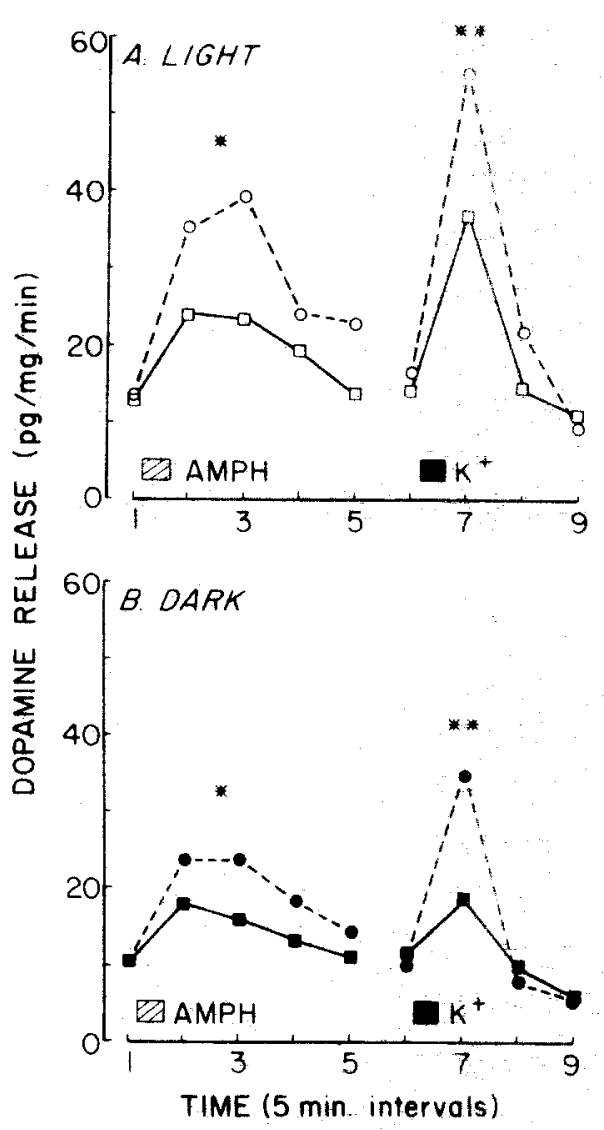

Fig. 1. The influence of light-dark cycle and estrogen plus progesterone $(E B+P)$ treatment on striatal dopamine $(D A)$ release stimulated by the infusion of $10 \mu \mathrm{M}$-amphetamine ( $\mathrm{AMPH})$ or $60 \mathrm{mM} \mathrm{KCl}\left(\mathrm{K}^{+}\right)$A during the light period of the light-dark cycle $(\square-\square: \mathrm{EB}+\mathrm{P} ; \bigcirc-\mathrm{O}:$ OIL); $\mathrm{B}$ : during the dark period of the light/dark cycle ( $\mathrm{EB}+\mathrm{P} ; \bigcirc$ : OIL). Animals pretreated with $\mathrm{EB}+\mathrm{P}$ released significantly more DA in response to AMPH stimulation than did oil treated controls $(P=0.017) . \mathrm{K}^{+}$-stimulated $D A$ release was significantly influenced by both hormone treatment and light cycle. There was greater $\mathrm{K}^{+}$-stimulated DA release in $\mathrm{EB}+\mathrm{P}$ treated animals than in oil treated controls $(P=$ $0.004)$ and there was a greater DA response to $\mathrm{K}^{+}$stimulation during the light than during the dark $(P=0.019)$. See text for details.

tion than did oil-treated control animals, regardless of the light-dark cycle (hormone treatment $x$ time interaction, $F(3,51)=488, P=0.004$; Fig. 1). In addition, $\mathrm{K}^{+}$induced more DA retease in animals killed during the light than in those killed during the dark, regardless of hormone treatment (light cycle $\times$ time interaction, $F(3,51)=3.59, P=0.019$; Fig. 1$)$.

AMPH and $\mathrm{K}^{+}$stimulate DA release by dissociable mechanisms. $\mathrm{K}^{+}$-stimulated $\mathrm{DA}$ release in vitro is calcium- and temperature dependent, and therefore 
is thought to involve exocytosis ${ }^{3,7,17,19}$. In contrast, AMPH-stimulated DA release is temperature- and sodium dependent, but calcium-independent $7,10,17$. These observations have been interpreted as indicating that AMPH releases non-vesicular DA by an energy-dependent mechanism relying on the integrity of the neuronal membrane. Since both AMPH- and $\mathrm{K}^{+}$-stimulated DA release were potentiated by hormone treatment, the effect of estrogen plus progesterone is probably not on the vesicular/nonvesicular distribution of DA. Instead, it would seem that ovarian hormones produce a more general increase in the responsiveness of striatal DA neurons to stimulation. Whether gonadal hormones act directly on nigrostriatal DA neurons, or influence striatal activity only by indirect means remains to be determined.

The influence of the light-dark cycle on $\mathrm{K}^{+}$-stimulated DA release was not entirely unexpected because other indices of striatal DA activity are known to show ultradian rhythms. For example, striatal DA concentrations, synthesis and turnover are increasing when the lights go on and begin to fall when the lights go off $9 \cdot 14,18$. This is consistent with our observation that $\mathrm{K}^{+}$-stimulated DA release was greater when the lights were on, a time when metabolic activity is on

1 Algeri, S., Ponzio, F., Dolfini, E. and Jori, A., Biochemical effects of treatment with oral contraceptive steroids on the dopaminergic system of the female rat, Neuroendocrinology, 22 (1976) 343-351.

2 Beatty, W. W., Gonadal hormones and sex differences in nonreproductive behaviors in rodents: organizational and activational influences, Horm. Behav., 12 (1979) 112-163.

3 Becker, J. B. and Ramirez, V. D., Dynamics of endogenous catecholamine release from brain fragments of male and female rats, Neuroendocrinology, 31 (1980) 18-25.

4 Becker, J. B. and Ramirez, V. D., Sex differences in the amphetamine stimulated release of catecholamines from rat striatal tissue in vitro, Brain Research, 204 (1981) 361-372.

5 Becker, J. B. and Robinson, T. E., Influences of estrogen on amphetamine-induced rotational behavior, Soc. Neurosci. Abstr., 9 (1983) 558

6 Becker, J. B., Robinson, T. E. and Lorenz, K. A., Sex differences and estrous cycle variations in amphetamine-elicited rotational behavior, Europ. J. Pharmacol., 80 (1982) $65-72$.

7 Becker, J. B., Castaneda, E., Robinson, T. E. and Beer, $M$. E., A simple in vitro technique to measure the release of endogenous dopamine and dihydroxyphenylacetic acid from striatal tissue using high performance liquid chromatography with electrochemical detection, J. Neurosci. Meth., (1984), in press. the increase, than when the lights were off and metabolic activity is decreasing. The finding that basal DA release was not influenced by the light cycle or hormonal treatment is not surprising, since basal DA efflux is both calcium- and temperature-independent ${ }^{7}$. Therefore, basal DA efflux would not necessarily be expected to reflect changes in striatal DA metabolism.

In closing, we would like to emphasize that the doses of estrogen and progesterone used in this experiment produce blood levels of these hormones within the normal physiological range8.12. This is in contrast to the pharmacological doses required to produce measurable changes in striatal DA receptor binding ${ }^{11,13}$. Therefore, it is very possible that ovarian hormone modulation of presynaptic striatal DA activity may underlie estrous cycle-dependent variations in behaviors mediated by the mesostriatal system 5.6 .16 , and in some other non-reproductive behaviors known to be influenced by ovarian hormones ${ }^{2}$.

We thank Marylin Hoy for typing the manuscript. Supported by NINCDS Grant NS16437 and NICHHD Grant HD05997.

8 Butcher, R. L., Collins, W. E. and Fugo, N. W., Plasma concentration of $\mathrm{LH}, \mathrm{FSH}$, prolactin, progesterone and estradiol-17 $\beta$ throughout the 4-day estrous cycle of the rat, Endocrinology, 94 (1974) 1704-1708.

9 Cahill, A. L. and Ehret, C. F., Circadian variations in the activity of tyrosine hydroxylase, tyrosine aminotransferase, and tryptophan hydroxylase: relationship to catecholamine metabolism, J. Neurochem., 37 (1981) 1109-1115.

10 Fischer, J. F. and Cho, A. K., Chemical release of dopamine from striatal homogenates: evidence for an exchange diffusion model, J. Pharmacol. exp. Ther., 208 (1979) 203-209.

11 Gordon, J. H. and Diamond, B. I., Antagonism of dopamine-supersensitivity by estrogen: neurochemical studies in an animal model of tardive dyskinesia, Biol. Psychiat., 16 (1981) 365-371.

12 Henderson, S. R., Baker, C. and Fink, G., Oestradiol-17 $\beta$ and pituitary responsiveness to luteinizing hormone releasing factor in the rat: a study using rectangular pulses of oestradiol-17 $\beta$ monitored by non-chromatographic radioimmunoassay, J. Endocrinol., 73 (1977) 441-453.

13 Hruska, R. E. and Silbergeld, E. K., Estrogen treatment enhances dopamine receptor sensitivity in the rat striatum, Europ. J. Pharmacol., 61 (1980) 397-400.

14 Lemmer, R. and Berger, T., Diurnal rhythm in the central dopamine turnover in the rat, Naunyn-Schmiedeberg's Arch. Pharmacol., 303 (1978) 257-261. 
15 Moore, K. E., Amphetamine: biochemical and behavioral actions in animals. In L. L. Iversen, S. D. Iversen and S. H. Snyder (Eds.), Handbook of Psychopharmacology, Vol. 11, Plenum Press, New York, 1978, pp. 41-98.

16 Robinson, T. E., Camp, D. M., Jacknow, D. S. and Becker, J. B., Sex differences and estrous cycle dependent variation in rotational behavior elicited by electrical stimulation of the mesostriatal dopamine system, Behav. Brain Res., 6 (1982) 273-287.

17 Schwarz, R. D., Uretsky, N. J. and Bianchine, J. R., The relationship between the stimulation of dopamine synthesis and release produced by amphetamune and high potassium in striatal slices, J. Neurochem., 35.(1980) 1120-1127.

18 Simon, M. L. and George, R., Diurnal variations in plasma corticosterone and growth hormone as correlated with regional variations in norepinephrine, dopamine and serotonin content of rat brain, Neuroendocrinology, 17 (1975) 125-138.

19 Takimoto, G. S., Stittsworth, J. D. and Stephens, J: K... $\left[{ }^{3} \mathrm{H}\right]$ Dopamine depletion from osmotically defined storage sites: effects of reserpine, $53 \mathrm{mM} \mathrm{KCl}$ and b-amphetamine, J. Neurochem. 41 (1983) 119-127. 